\title{
The responses of blood galactose to oral doses of lactose, galactose plus glucose and milk to piglets
}

\author{
BY P. H. BIRD, C. S. ATWOOD AND P. E. HARTMANN \\ Department of Biochemistry, University of Western Australia, Nedlands WA 6009, Australia
}

(Received 30 March 1994-Accepted 24 August 1994)

\begin{abstract}
The capacity of intestinal lactase (EC 3.2.1.23) of piglets to hydrolyse lactose in vivo was investigated by measuring the response of blood galactose to doses of lactose, galactose plus glucose and both whole and skimmed milk. Following the administration of oral doses of lactose dissolved in water to piglets from 2 to $18 \mathrm{~d}$ of age the adjusted galactose area under the curve (AUC) was between 1.12 and 1.36 arbitrary units, while following a dose of galactose plus glucose dissolved in water it was between 1.56 and 1.98 arbitrary units. Whereas these results suggest that the rate of digestion of lactose appeared to limit the amount of galactose reaching the peripheral blood after a dose of lactose dissolved in water, there was no significant correlation between the capacity of piglets to hydrolyse physiological amounts of lactose and the age of the piglets (2- to 18-d-old piglets; $r$ 0.11). Following oral doses of sow's milk containing either lactose, or galactose plus glucose, the adjusted galactose AUC values were 0.94 and 1.00 arbitrary units respectively, in 10-d-old piglets. Thus, the limitation to the digestion of lactose observed when it was present in water was not evident for lactose in sow's milk. Since there was no significant difference between the adjusted galactose AUC following a dose of whole milk ( 0.95 arbitrary units) and that following a dose of skimmed milk (1.03 arbitrary units), the presence of fat in sow's milk did not appear to affect the utilization of lactose by the sucking piglets.
\end{abstract}

Piglet: Lactose: Milk: Blood: Galactose

Manners \& Stevens (1972) demonstrated that the in vitro specific activity of intestinal lactase (EC 3.2.1.23) in the pig is high at birth, falls rapidly until 2 weeks of wage and then gradually decreases to reach adult levels by 8 weeks of age. Similarly, James et al. (1987) reported that, while lactase activity remained high during the first $10 \mathrm{~d}$ post partum, this activity fell during the following $6 \mathrm{~d}$ and remained constant to $24 \mathrm{~d}$. However, based on the calculation of total intestinal lactase, the capacity of intestinal lactase to hydrolyse lactose was shown by Walker (1959) and Ekstrom et al. (1975) to be at a maximum between 15 and $21 \mathrm{~d}$ of age.

We have investigated the digestion of lactose in the sucking piglet using in vivo techniques (Bird \& Hartmann, 1994) based on the changes in the concentration of galactose in the peripheral plasma following oral doses of both lactose and galactose plus glucose present in either water or sow's milk. We tested the hypothesis that piglets from 2 to $18 \mathrm{~d}$ of age have a similar capacity to digest lactose. Since milk with a low fat content can decrease the utilization of lactose by infants (Woolridge \& Fisher, 1988) and rats (Fischer \& Sutton, 1949), we also investigated the influence of the presence of fat in sow's milk on the changes in the concentration of galactose in the peripheral plasma of sucking piglets by comparing the effect of oral doses of whole and skimmed milk. 


\section{MATERIALS AND METHODS}

\section{Animals}

Piglets (Landrace, Large White or Landrace $\times$ Large White) used in the present study were housed at Wandalup Farms Piggery, Mandurah, Western Australia. Healthy 2-, 5-, 10-, $15-$ and 18-d-old piglets ( $n 5,6,5,10$ and 4 respectively) with mean body weights of $2 \cdot 0$ (SE $0 \cdot 2$ ), 2.6 (SE 0.3), 3.5 (SE 0.4), 5.2 (SE 0.4) and 5.4 (SE 0.8) kg respectively were given oral doses of either galactose plus glucose or lactose dissolved in water (Expt 1). Healthy 10-d-old piglets ( $n$ 19) with a mean body weight of 3.4 (SE 0.4 ) $\mathrm{kg}$ received oral doses of sow's milk (Expt 2). In both experiments the groups of test animals were compiled from different litters, and no more than two piglets were selected at random from any one litter. The piglets were separated from their sow by partitioning the farrowing crate.

\section{Preparation of oral doses}

In Expt 1, the carbohydrate solutions were prepared by dissolving either $0.675 \mathrm{~g}$ galactose plus $0.675 \mathrm{~g}$ glucose in $15 \mathrm{ml}$ deionized water (GAL+GLU treatment) or $1.35 \mathrm{~g}$ lactose in $15 \mathrm{ml}$ deionized water (LAC treatment).

In Expt 2 the milk samples were collected from twenty unrestrained sows (5-10 d post partum) by inducing milk let-down with an injection of 1 IU synthetic oxytocin (Pitocin, Parke Davis and Co., Victoria Park, Western Australia) into the middle ear vein of each sow. Milk was expressed from four to five glands on each sow and pooled into glass bottles $(200 \mathrm{ml})$ which were then frozen in a portable freezer (Engel; Sawafuji Electric Co. Ltd., Leederville, Western Australia) for transport back to the laboratory. The milk was stored at $-80^{\circ}$. Approximately 1 litre of milk was collected.

While about $300 \mathrm{ml}$ of the collected milk remained untreated (whole milk, WM), about $600 \mathrm{ml}$ was thawed at $37^{\circ}$ and mixed gently. Five drops of lactase (Lactaid ${ }^{\circledR}$, Lactaid Inc., Pleasantville, NJ 08232, USA) was added to $300 \mathrm{ml}$ thawed milk to hydrolyse the lactose to galactose plus glucose (hydrolysed whole milk, HWM). The remaining $300 \mathrm{ml}$ of this thawed milk was then transferred into plastic centrifuge tubes in $40 \mathrm{ml}$ portions and skimmed milk was prepared by centrifuging at $3900 \mathrm{~g}$ for $10 \mathrm{~min}$ at $4^{\circ}$ and removal of the fat layer (skimmed milk, SM). Three drops of lactase were added to $150 \mathrm{ml}$ of this milk to produce a skimmed milk containing galactose and glucose (hydrolysed skimmed milk, HSM). The different batches of milk were then divided into individual doses $(20 \mathrm{ml})$ for oral administration to the piglets. The concentrations of lactose, galactose, glucose, fat and protein in each dose of milk were determined (see Table 1).

\section{Dosing regimes}

In Expt 1 the solution $(15 \mathrm{ml})$ containing the GAL+GLU treatment was administered orally to each piglet, followed 90 min later by the LAC treatment.

In Expt 2 the following groups of piglets received $20 \mathrm{ml}$ doses of milk treated as described above and in Table 1: group 1, WM, followed 90 min later by HWM ( $n$ 6); group 2, WM, followed 90 min later by SM ( $n$ 7); group 3, HWM, followed 90 min later by HSM ( $n$ 6).

\section{Oral doses and blood sampling}

Piglets were treated with oral doses of either carbohydrate dissolved in water or milk collected from sows. The piglets were fasted for at least $1 \mathrm{~h}$ before an initial oral dose was administered and a second oral dose was administered 90 min later. The administration time for each dose was between 0.5 and $2 \mathrm{~min}$, zero time being taken as the time when half of the volume of the solution had been administered. Blood samples were collected just 
Table 1. Concentrations of lactose, galactose plus glucose, fat and protein in different milk preparations used as oral doses for each of three groups of 10-d-old piglets*

(Mean values with their standard errors)

\begin{tabular}{|c|c|c|c|c|c|c|c|c|}
\hline \multirow[b]{2}{*}{ Treatment } & \multicolumn{2}{|c|}{$\begin{array}{l}\text { Lactose } \\
(\mathrm{g} / \mathrm{l})\end{array}$} & \multicolumn{2}{|c|}{$\begin{array}{l}\text { Galactose plus } \\
\text { glucose }(\mathrm{g} / 1)\end{array}$} & \multicolumn{2}{|c|}{ Fat $(\mathrm{g} / \mathrm{l})$} & \multicolumn{2}{|c|}{ Protein $(g / 1)$} \\
\hline & Mean & SE & Mean & $\mathrm{SE}$ & Mean & $\mathrm{SE}$ & Mean & $\mathrm{SE}$ \\
\hline $\begin{array}{l}\text { Group 1 } \\
\text { WM } \\
\text { HWM } \\
\text { Significance }\end{array}$ & \multicolumn{2}{|c|}{$\begin{aligned} & <4.0 \\
P & <0.001\end{aligned}$} & $\begin{array}{c}61 \cdot 7 \\
P<\end{array}$ & 1.8 & $\begin{array}{l}91 \cdot 3 \\
95 \cdot 1\end{array}$ & $\begin{array}{l}2 \cdot 0 \\
2 \cdot 0\end{array}$ & $\begin{array}{l}47.2 \\
45 \cdot 0\end{array}$ & $\begin{array}{l}0.6 \\
0.5\end{array}$ \\
\hline $\begin{array}{l}\text { Group } 2 \\
\text { WM } \\
\text { SM } \\
\text { Significance }\end{array}$ & $\begin{array}{l}57 \cdot 2 \\
56 \cdot 2\end{array}$ & $\begin{array}{l}0.6 \\
1.9\end{array}$ & & $\begin{array}{l}<0.2 \\
<0.2\end{array}$ & $\begin{array}{c}90 \cdot 0 \\
9.2 \\
P<\end{array}$ & $\begin{array}{l}3.0 \\
1.0 \\
01\end{array}$ & $\begin{array}{l}45 \cdot 2 \\
44 \cdot 7\end{array}$ & $\begin{array}{l}0-8 \\
0-3\end{array}$ \\
\hline $\begin{array}{l}\text { Group } 3 \\
\text { HWM } \\
\text { HSM } \\
\text { Significance }\end{array}$ & & & $\begin{array}{l}58 \cdot 0 \\
60 \cdot 5\end{array}$ & $\begin{array}{l}2 \cdot 6 \\
1 \cdot 2\end{array}$ & $\begin{array}{c}85.8 \\
11.6 \\
P<\end{array}$ & $\begin{array}{r}2.0 \\
1.0 \\
01\end{array}$ & $\begin{array}{l}45 \cdot 5 \\
44 \cdot 7\end{array}$ & $\begin{array}{l}1-0 \\
0-4\end{array}$ \\
\hline
\end{tabular}

WM, whole milk; HWM, hydrolysed whole milk; SM, skimmed milk; HSM, hydrolysed skimmed milk; NS, not significant.

* For details of milks and procedures, see pp. 754-756.

before each oral dose and at 3-10 min intervals for $40 \mathrm{~min}$ and then at $60 \mathrm{~min}$ after the dose. Blood ( $50-60 \mu \mathrm{l})$ was collected and plasma prepared and stored as described by Bird \& Hartmann (1994).

\section{Biochemical analysis}

Milk. A portion of each sample of milk $(400 \mu \mathrm{l})$ was centrifuged for $10 \mathrm{~min}$ at $10000 \mathrm{~g}$ at $4^{\circ}$ in $450 \mu \mathrm{l} \mathrm{Kartell}{ }^{\circledR}$ microcentrifuge tubes (Crown Scientific, Perth, Western Australia). The resulting fat layer was removed by slicing the tube just below the fat layer and the defatted milk was deproteinized with perchloric acid according to the method of Arthur et al. $(1989 a)$.

The concentration of glucose in the defatted and deproteinized milk samples was measured using the method of Kunst et al. (1985) and adjusted for measurement on a Titertek Multiskan MCC/340 spectrophotometer (Flow Laboratories, Perth, Western Australia). The concentration of galactose in the defatted and deproteinized milk samples was measured using the method of Kulski \& Buehring (1982) and modified for measurement on a Titertek Multiskan. The concentration of lactose in the defatted and deproteinized milk samples was measured using a modification of the method described by Arthur $e t$ al. $(1989 \mathrm{~b})$. The concentration of glucose was measured in defatted and deproteinized milk in which the lactose had been hydrolysed to galactose and glucose by diluting the sample 1:60 with double deionized water and then using the same protocol as that for lactose (Arthur et al. $1989 \mathrm{~b}$ ), except that glucose standards were used in place of lactose and the lactase digestion step was omitted.

The concentration of fat in the different doses of milk was measured using the esterified fatty acid method of Stern \& Shapiro (1953) as modified by Atwood \& Hartmann (1992). The concentration of protein in the different doses of milk was determined using the method of Lowry et al. (1951) as modified by Hess et al. (1978) and Atwood \& Hartmann (1992). 
Plasma. The plasma $(20 \mu \mathrm{l})$ was deproteinized with $200 \mu 10.6 \mathrm{M}$-perchloric acid according to the method of Arthur et al. $(1989 a)$ and the concentration of galactose was determined by the bioluminescence method of Arthur et al. (1989a).

\section{Data analysis}

Following oral dosing, the concentrations of galactose in the blood were plotted against time, and the area under the curve (AUC) between 0 and $60 \mathrm{~min}$ for each piglet was calculated by the trapezoid method reported by Williams et al. (1983), which was derived from Yeh \& Kwan (1978). Since piglets of different body weights were given the same amount of galactose, the heavier piglets distributed the absorbed monosaccharide in a larger volume of plasma. Therefore, it was necessary to adjust the AUC to account for the different dilution of the monosaccharide in piglets of different weights (adjusted galactose AUC) as described by Bird \& Hartmann (1994).

Each piglet's capacity to digest a dose of lactose was determined from the adjusted galactose AUC following a dose of lactose, relative to that following an equivalent dose of galactose plus glucose. The relative digestive capacity for lactose (index of the efficiency of lactose digestion) by each piglet was calculated using the following formula: adjusted galactose AUC (treatment LAC)/adjusted galactose AUC (treatment GAL + GLU) $\times$ $100 \%$.

\section{Statistical analysis}

Milk analysis. Comparisons of the concentrations of lactose, galactose plus glucose, fat and protein in the different milk preparations were analysed with unpaired $t$ tests within the different groups (Table 1). It was not appropriate to test differences in the concentrations of these nutrients between the different groups.

Carbohydrate-in-water treatments. Following GAL + GLU and LAC treatments, which were administered to the same piglets in each age group, differences in peak concentrations of galactose and the times taken to reach the peak concentrations within each age group were compared with paired $t$ tests (Table 2). However, the values for the galactose AUC were adjusted so that the different age groups could be compared and this analysis was carried out with a split-plot, two-way analysis of variance (Table 2).

Carbohydrate-in-milk treatments. Both types of treated milk used in each group were administered to each piglet within that group and, therefore, differences in peak concentrations of galactose, the times taken to reach the peak concentrations and the adjusted galactose AUC were compared within each age group with paired $t$ tests (Table 3). It was not appropriate to test differences between the different groups.

Significant differences. Significant differences within each age group are denoted by similar superscripts and the level of significance is shown by the $P$ value. No significant difference $(P>0.05)$ is denoted by NS. Results are expressed as means with their standard errors, SEM (average SEM for analysis of variance). Statistical analysis was determined using StatView, SE + Graphics ${ }^{\text {II }}$ I, v1.03 (Abacus Concepts Inc. Berkeley, USA).

\section{RESULTS \\ Carbohydrate in water}

The mean concentrations of galactose in the plasma of the different aged piglets after a dose of galactose plus glucose (GAL + GLU treatment) followed $90 \mathrm{~min}$ later by a dose of lactose (LAC treatment) were determined and an example showing the results for the 2-dold piglets is illustrated in Fig. 1. The peak concentration of galactose and the time taken to reach this peak was determined for individual piglets, and the mean for each treatment 


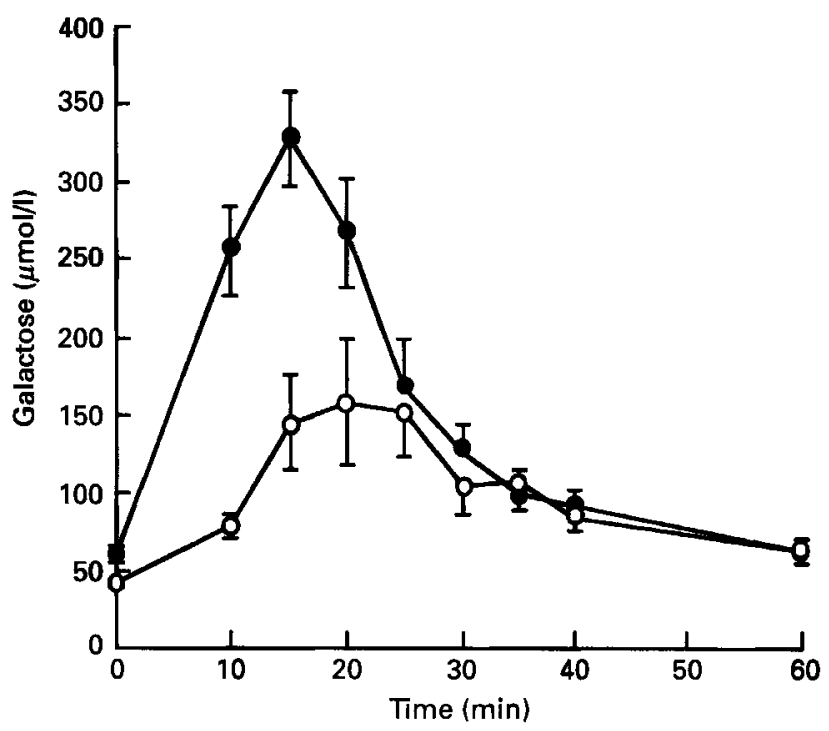

Fig. 1. The concentrations of galactose in the plasma over time in 2-d-old piglets following an oral dose of galactose plus glucose $(0, n 5)$ and an oral dose of lactose $(O, n 5)$ administered in $15 \mathrm{ml}$ water.

calculated and compared using a paired $t$ test (Table 2). The mean peak concentrations of galactose following the GAL + GLU treatment were significantly higher than the mean peak concentrations of galactose following the LAC treatment in all age groups (Table 2). The mean peak galactose concentration decreased with increasing age of the piglets for both GAL+GLU and LAC treatments (Table 2). However, there was no significant difference in the time taken to reach the peak after each of the treatments in all age groups (Table 2).

Although an analysis of variance test showed that there was a marginally significant difference $(P<0.05)$ in the adjusted galactose AUC between the 5-d-old piglets and the 2and 10 -d-old piglets after the GAL + GLU treatment, there was no significant difference in the adjusted galactose AUC between the different age groups of piglets after the LAC treatment. However, there was a significant difference in the adjusted galactose AUC within each age group between the GAL + GLU and LAC treatments. There was no significant correlation $(r 0 \cdot 11, n 30)$ between the index for the efficiency of lactose digestion and the different age groups of piglets.

\section{Carbohydrate in milk}

The peak concentration of galactose and the time taken to reach this peak were determined for individual piglets and the mean for each treatment was calculated and compared using a paired $t$ test (Table 3). In group 1 (WM and HWM treatments) the peak concentration of galactose was significantly higher and the time taken to reach peak concentration was significantly shorter after the HWM treatment, compared with the WM treatment. However, there was no significant difference in the adjusted galactose AUC between the WM and HWM treatments (group 1, Table 3). In group 2(WM and SM treatments), where all doses contained milk with intact lactose, there was no significant difference between the peak concentration of galactose, the time taken to reach peak concentration or the adjusted galactose AUC between the WM and SM treatments (Table 3). Similarly, in group 3 (HWM, and HSM treatments), where all doses contained milk in which lactose had been 
Table 2. Peak concentrations of galactose, times taken to reach the peak concentrations, adjusted areas under the galactose curve $(A U C)$ and the index for the efficiency of lactose digestion following doses of galactose plus glucose $(G A L+G L U)$ and lactose $(L A C)$ in piglets*

(Mean values with their standard errors)

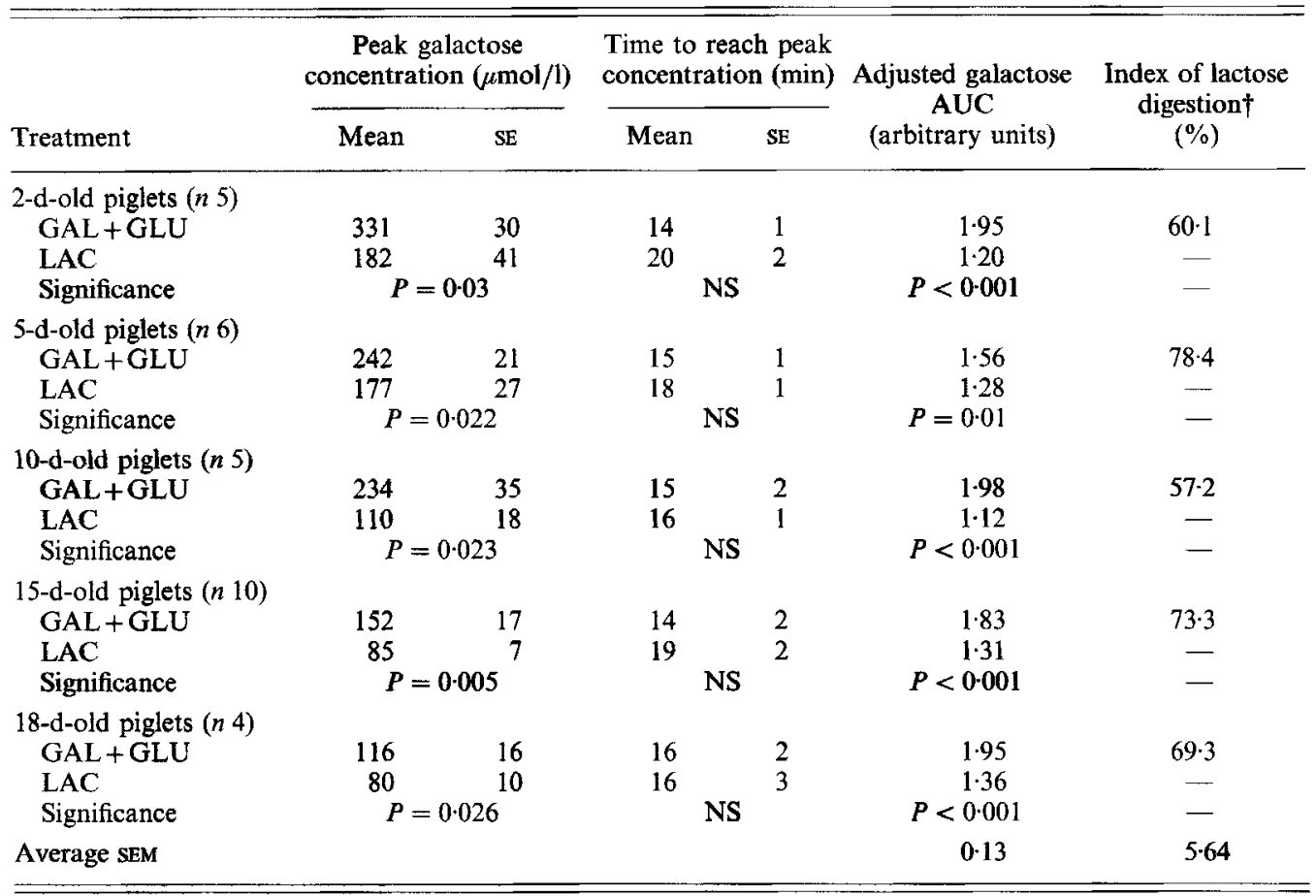

NS, not significant.

* For details of treatments and procedures, see pp. 754-756.

$\uparrow$ Calculated from the formula: adjusted galactose AUC (treatment LAC)/adjusted galactose AUC (treatment $\mathrm{GAL}+\mathrm{GLU}) \times 100$.

hydrolysed to galactose plus glucose, there was no significant difference between either the peak concentration of galactose, the time taken to reach peak concentration or the adjusted galactose AUC between the HWM treatment and HSM treatment (Table 3).

\section{DISCUSSION}

When the oral doses of carbohydrate in water were administered to piglets, both the adjusted galactose AUC and the peak concentration of galactose in the plasma (Table 2) after the GAL+GLU treatment were significantly higher than that after the LAC treatment within each age group. This difference could be due to either the incomplete digestion of lactose reducing the amount of galactose presented for absorption, or an increased metabolic clearance of galactose following the LAC treatment. We have previously shown that, given sufficient time for the intestinal absorption of galactose and its distribution in extracellular water, there was no significant difference in the half-life of galactose in the blood of piglets between either oral or intravenous doses of galactose (Bird 
Table 3. Peak concentration of galactose in plasma, time to reach the peak, and the adjusted area under the galactose curve $(A U C)$ in the plasma of three groups of 10-d-old piglets following oral doses of different batches of milk*

(Mean values with their standard errors for five piglets)

\begin{tabular}{|c|c|c|c|c|c|c|}
\hline \multirow[b]{2}{*}{ Treatment } & \multicolumn{2}{|c|}{$\begin{array}{l}\text { Peak galactose } \\
\text { concentration } \\
(\mu \mathrm{mol} / 1)\end{array}$} & \multicolumn{2}{|c|}{$\begin{array}{l}\text { Time to reach } \\
\text { peak concentration } \\
\text { (min) }\end{array}$} & \multicolumn{2}{|c|}{$\begin{array}{c}\text { Adjusted galactose } \\
\text { AUC } \\
\text { (arbitrary units) }\end{array}$} \\
\hline & Mean & $\mathbf{S E}$ & Mean & SE & Mean & $\mathbf{S E}$ \\
\hline \multicolumn{7}{|l|}{ Group 1} \\
\hline WM & 79 & 14 & $21 \cdot 5$ & $2 \cdot 0$ & 0.94 & $0 \cdot 17$ \\
\hline HWM & 101 & 13 & $15 \cdot 3$ & 0.9 & 1.00 & $0 \cdot 13$ \\
\hline Significance & \multicolumn{2}{|c|}{$P=0.012$} & \multicolumn{2}{|c|}{$P=0.032$} & \multicolumn{2}{|c|}{ NS } \\
\hline \multicolumn{7}{|l|}{ Group 2} \\
\hline WM & 112 & 27 & $14 \cdot 2$ & $3 \cdot 0$ & 0.95 & 0.12 \\
\hline SM & 132 & 20 & $13 \cdot 7$ & 3.0 & 1.03 & $0 \cdot 12$ \\
\hline Significance & \multicolumn{2}{|c|}{ NS } & \multicolumn{2}{|c|}{ NS } & \multicolumn{2}{|c|}{ NS } \\
\hline \multicolumn{7}{|l|}{ Group 3} \\
\hline HWM & 91 & 13 & $16 \cdot 3$ & 1.9 & 0.98 & 0.13 \\
\hline HSM & 123 & 37 & $19 \cdot 3$ & 3.0 & $1 \cdot 20$ & 0.06 \\
\hline Significance & \multicolumn{2}{|c|}{ NS } & \multicolumn{2}{|c|}{ NS } & \multicolumn{2}{|c|}{ NS } \\
\hline
\end{tabular}

WM, whole milk; HWM, hydrolysed whole milk; SM, skimmed milk; HSM, hydrolysed skimmed milk; NS, not significant.

* For details of milks and procedures, see Table 1 and pp. 754-756.

\& Hartmann, 1994). Therefore, the protocol in the present study would not be expected to change the clearance of galactose from the blood. Thus our results suggest that less total galactose reached the peripheral plasma from the dose of lactose compared with that from an equivalent dose of galactose plus glucose (Table 2). Assuming that the AUC for galactose is proportional to the amount of galactose available for absorption in the small intestine, an index of the efficiency of lactose digestion over $60 \mathrm{~min}$ can be calculated from the ratio of the adjusted galactose AUC for the LAC $v$. GAL + GLU treatments. This index indicates that the amount of galactose absorbed from the small intestine when galactose was presented as lactose in water averaged between 57.2 and $78.4 \%$ of that when presented as galactose plus glucose in water to 2 - to 18 -d-old piglets (Table 2). It follows that the rate of lactose hydrolysis by intestinal lactase limited galactose absorption. However, the in vitro studies of Walker (1959) showed that $5.9 \mathrm{~g}$ and $0.8 \mathrm{~g}$ lactose was hydrolysed/ $\mathrm{kg}$ body weight per $h$ in newborn and 5-week-old piglets respectively. Since the piglets in the present study ranged in body weight from 2.0 (SE 0.2) kg (2-d-old) to 5.4 (SE 0.8) kg (18-d-old) and all piglets ingested $1.35 \mathrm{~g}$ of lactose (LAC treatment), the capacity of intestinal lactase to hydrolyse lactose should not have been exceeded.

Previous studies in piglets have demonstrated that the activity of lactase declines over the first few weeks after birth when expressed as activity per unit weight of intestinal tissue (Bailey et al. 1956; Walker, 1959; Hartman et al. 1961; Manners \& Stevens, 1972; Ekstrom et al. 1975; Widdowson et al. 1976; James et al. 1987). However, due to the rapid growth of the intestine at this time, the total activity of lactase present in the intestine was found to be at a maximum at 15-21 d of age (Walker, 1959; Ekstrom et al. 1975). Our results have shown that the index for the efficiency of lactose digestion did not change in piglets from 2 to $18 \mathrm{~d}$ of age (Table 2). Therefore, although the specific activity of lactase declines with 
age, we conclude that the capacity of the small intestine of the piglets to hydrolyse physiological doses of lactose does not decline from 2 to $18 \mathrm{~d}$ of age.

Since the index for the efficiency of lactose digestion for carbohydrate in water was not significantly different $(P>0.05)$ from 2 to $18 \mathrm{~d}$ of age, the efficiency of lactose digestion in milk was examined only in 10-d-old piglets. In contrast to the lower adjusted galactose AUC for the LAC compared with the GAL + GLU treatments in water (Table 2), there was no significant difference in the adjusted galactose AUC between whole milk (WM treatment) and whole milk in which lactose was hydrolysed to galactose plus glucose (HWM treatment; group 1, Table 3). However, the mean peak concentration of galactose in the plasma (group 1, Table 3) was significantly lower and delayed $(P<0.05)$ following the WM treatment compared with the HWM treatment. Therefore, although the time taken to hydrolyse lactose appeared to limit the rate of appearance of galactose in the peripheral plasma, the total amount of galactose absorbed into the peripheral plasma over 60 min (i.e. the adjusted galactose AUC) was unaffected. The difference between the index for the efficiency of lactose digestion when lactose was present in whole milk (93.7 (SE 0.08) \%, $n$ 6) compared with water (68.9 (SE 2.8) \%, $n 30$ ) suggests that other constituents in milk either facilitated the digestion of lactose or reduced the amount of galactose entering the peripheral blood from a dose of milk containing hydrolysed lactose.

The addition of fat to diets containing lactose markedly reduced the digestion of lactose in weanling rats (Nieft \& Deuel, 1947). Although the cause of this effect is not clear, the presence of fat in the diet has been shown to slow the rate of gastric emptying in adult pigs (Gregory et al. 1989) and man (Cooke, 1975). Furthermore, Woolridge \& Fisher (1988) suggested that infants whose mothers had an over-supply of breast milk consumed mainly fore milk, which is normally low in fat. Consequently, they argued that gastric release should be accelerated, reducing the amount of lactose hydrolysed in the small intestine and that the excess lactose entering the large intestine could induce carbohydrate intolerance. The results from the present study showed that the absence of fat (SM and HSM treatments) did not affect the adjusted galactose AUC, peak galactose concentration or time to reach peak concentration in the plasma compared with whole milk (WM and HWM treatments, groups 2 and 3, Table 3). Therefore, at least in the piglet, the concentration of fat in sow's milk does not appear to have any significant functional effect on either gastric release of simple carbohydrates or lactose hydrolysis and galactose absorption.

We would like to thank Melinda Hartmann, Sandra Pember and Janine Toussaint for their excellent technical assistance, Wandalup Farms for the availability of the piglets and their facilities and to acknowledge the Pig Research and Development Corporation for granting both a junior research fellowship and the financial support for this project.

\section{REFERENCES}

Arthur, P. G., Kent, J. C. \& Hartmann, P. E. (1989 a). Milk lactose, citrate and glucose as markers of lactogenesis in normal and diabetic women. Journal of Pediatric Gastroenterology and Nutrition 9, 488-496.

Arthur, P. G., Kent, J. C. \& Hartmann, P. E. $(1989 \mathrm{~b})$. Microanalysis of the metabolic intermediate of lactose synthesis in human milk and plasma using bioluminescent methods. Analytical Biochemistry 176, 449-456.

Atwood, C. S. \& Hartmann, P. E. (1992). Collection of fore and hind milk from the sow and the changes in milk composition during suckling. Journal of Dairy Research 59, 287-298.

Bailey, C. B., Kitts, W. D. \& Wood, A. J. (1956). The development of the digestive enzyme system of the pig during its pre-weaning phase of growth. Canadian Journal of Agricultural Science 36, 51-59.

Bird, P. H. \& Hartmann, P. E. (1994). The response in the blood of piglets to oral doses of galactose and glucose and intravenous administration of galactose. British Journal of Nutrition 71, 553-561.

Cooke, A. R. (1975). Control of gastric emptying and motility. Gastroenterology 68, 804-816.

Ekstrom, K. E., Benevenga, N. J. \& Grummer, H. (1975). Changes in the intestinal lactase activity in the small intestine of two breeds of swine from birth to 6 weeks of age. Journal of Nutrition 105, 1032-1038. 
Fischer, J. E. \& Sutton, T. S. (1949). Effects of lactose on gastro-intestinal motility: a review. Journal of Dairy Science 32, 139-162.

Gregory, P. C., McFadyn, M. \& Rayner, D. V. (1989). Control of gastric emptying in the pig: influence of duodenal infusions of glucose and emulsified fat. Quarterly Journal of Experimental Physiology 74, $109-119$.

Hartman, P. A., Hays, V. W., Baker, R. O., Neagle, L. H. \& Catron, D. V. (1961). Digestive enzyme development in the young pig. Journal of Animal Science 20, 114-123.

Hess, H. H., Lees, M. B. \& Derr, J. E. (1978). A linear Lowry-Folin assay for both water-soluble and sodium dodecyl sulphate-solubilized proteins. Analytical Biochemistry 85, 295-300.

James, P. S., Smith, M. W., Tivey, D. R. \& Wilson, T. J. G. (1987). Epidermal growth factor selectively increases maltase and sucrase activities in neonatal piglet intestine. Journal of Physiology 393, 583-594.

Kulski, J. K. \& Buehring, G. C. (1982). Microanalysis of lactose in tissue culture medium using an enzymaticfluorometric method. Analytical Biochemistry 119, 341-350.

Kunst, A., Draeger, B. \& Ziegenhorn, J. (1985). 2.4 D-glucose. 2.4.1. UV-methods with hexokinase and glucose6-phosphate dehydrogenase. In Methods of Enzymatic Analysis, Vol. 6, pp. 163-172 [H. U. Bergmeyer, J. Bergmeyer and M. Grabl, editors]. Weinheim: Verlag, Chemie.

Lowry, O. H., Rosebrough, N. J., Farr, A. L. \& Randall, R. J. (1951). Protein measurement with the Folin phenol reagent. Journal of Biological Chemistry 193, 265-275.

Manners, M. J. \& Stevens, J. A. (1972). Changes from birth to maturity in the pattern of distribution of lactase and sucrase activity in the mucosa of the small intestine of pigs. British Journal of Nutrition 28, $113-127$.

Nieft, M. L. \& Deuel, H. J. (1947). The effect of fat on the absorption and utilisation of galactose by the rat. Journal of Biological Chemistry 167, 521-525.

Stern, I. \& Shapiro, B. (1953). A rapid and simple method for the determination of esterified fatty acids and for total fatty acids in blood. Journal of Clinical Pathology 6, 158-160.

Walker, D. M. (1959). The development of the digestive system of the young animal. II. Carbohydrase enzyme development in the young pig. Journal of Agricultural Science 52, 357-363.

Widdowson, E. M., Colombo, V. E. \& Artavanis, C. A. (1976). Changes in the organs of pigs in response to feeding for the first 24 hours after birth. II. The digestive tract. Biology of the Neonate 28, 272-281.

Williams, C. A., Philips, T. \& Macdonald, I. (1983). The influence of glucose on serum galactose levels in man. Metabolism 32, 250-256.

Woolridge, M. W. \& Fisher, C. (1988). Colic, 'overfeeding', and symptoms of lactose malabsorption in the breastfed baby: a possible artefact of feed management? Lancet 2, 382-385.

Yeh, K. C. \& Kwan, K. C. (1978). A comparison of numerical integrating algorithms by trapezoidal, lagrange and spline approximation. Journal of Pharmacokinetics and Biopharmaceutics 6, 79-98. 